\title{
PROFESSORES EM ESCOLAS PÚBLICAS DE EDUCAÇÃO BÁSICA: GESTORES DE SUAS AÇÕES E ATIVIDADES NO PROCESSO DE CONSTITUIÇÃO E DESENVOLVIMENTO DO TRABALHO DOCENTE
}

http://dx.doi.org/10.5902/2318133818846

\author{
Mirian Zimermann \\ Instituto Federal Farroupilha - campus de São Vicente do Sul, Brasil.
}

\begin{abstract}
Resumo
Neste texto tem-se como objetivo relatar uma pesquisa sobre o trabalho de professores que atuam em escolas públicas de ensino médio de Santa Maria, RS. Para tanto, a pesquisa guiou-se pelas caracterizações das diferentes ações realizadas pelos professores e como estes gerenciam suas ações no planejamento e realização de seu trabalho. Baseada em uma pesquisa de natureza qualitativa, teve como fontes de informação seis professores, os quais foram entrevistados individualmente. Concluiu-se que as diferentes ações dos docentes se condicionam pelas restritas condições oferecidas, levando-os a gerenciarem tais ações de forma simplificada. A alta carga horária é apenas uma das limitações que influenciam na realização do trabalho docente.

Palavras-chave: trabalho docente, prescrições, atividades, ações.
\end{abstract}

\section{TEACHERS IN PUBLIC SCHOOLS BASIC EDUCATION: THEIR ACTIONS MANAGERS AND ACTIVITIES IN THE PROCESS OF SETTING UP AND TEACHING JOB EVELOPMENT}

\begin{abstract}
This article aims to present report a the research about the work of teachers that that operate in public high schools from Santa Maria-RS. Therefore, the research was guided by characterizations the different actions in the realized by the teachers and how these managed your actions in the planning and realization from your work. Based in the qualitative research had sources from information six teachers, which was interviewed individually. Concludes that the different organizations from teachers mutually conditioned by the strict conditions offered, taken the manage such actions measure is a simplified. The work load is only a from limitations that influence in the realization from teaching work. Key-words: teaching work, prescriptions, activities, actions.
\end{abstract}




\section{Introdução}

Ivemos um período de contradições na sociedade. Os avanços tecnológicos ocorrem quase que diariamente e confrontamo-nos com fracasso escolar: evasão, reprovação baixos índices de escolaridade. Esta situação tem gerado problemas de ordens sociais, ambientais, políticas e econômicas.

Neste contexto o professor atua com a necessidade de inovar e renovar a sua maneira de ensinar, a fim de instigar no aluno maior interesse para a educação formal, inserindo-o na sociedade, sem deixar de realizar as demais funções de seu trabalho. O professor torna-se, então, em um ator social, pois, seu trabalho não se desenvolve apenas dentro de uma sala de aula, mas também na vida dos alunos.

Nosso interesse nessa temática está relacionado com os estudos dedicados à compreensão da educação e a necessidade da inserção de ações, políticas e propostas que potencializem a melhoria da formação e da atuação desses profissionais. Esse direcionamento deixa o trabalho docente e as formas de gestão com que os professores executam as diferentes atividades como o foco de nossos estudos. Para tanto, temos a necessidade de conhecermos melhor a escola, lócus onde se realiza o trabalho docente, e como a maneira que o professor articula as ações de seu trabalho proporciona o seu desenvolvimento profissional. Portanto, faz-se necessário compreendermos o que os docentes executam em suas atividades cotidianas, bem como caracterizar o seu local de trabalho.

\section{Escola, ambiente com muitas singularidades}

A escola foi constituída com o objetivo de alfabetizar indivíduos a fim de prepará-los para que consigam viver em sociedade. Sua organização está baseada no currículo e nas práticas pedagógicas.

No entanto, compreendê-la e interpretá-la não é fácil, pois, a escola é um espaço social no qual atuam diversos indivíduos e cada um com suas peculiaridades, o que a torna com muitas heterogeneidades e diversidades. O espaço social escolar é composto por relações formais e informais, abrigando tensões, negociações, conflitos e ajustes em suas relações. As relações formais são as que ocorrem na hora do trabalho como, por exemplo, as que ocorrem entre os professores nas horas de reuniões pedagógicas, entre os demais funcionários nas divisões e execuções das atividades, entre professor e aluno durante as aulas e professores e pais. Já as relações informais são aquelas que abordam laços de amizades que se formam no local de trabalho e que, muitas vezes, estendem-se para a vida pessoal.

A educação escolar brasileira possui marcas históricas de seu processo de constituição que ainda estão presentes em muitos pensamentos e práticas da escola atual. Sendo assim, ao tentarmos compreender a escola como um espaço educativo devemos analisar cada situação escolar e seu contexto, cada atividade cotidiana dos docentes, pois, nenhum problema ou aspecto da organização escolar acontece sozinho e, consequentemente, não deve ser enfocado isoladamente. 
Santos (2011) ressalta a importância de observar todo o contexto das situações escolares quando afirma que

para estudos que visam [a] compreender este espaço institucional, perceber essas diferenças é uma condição importante, pois, não podemos correr o risco de olhar a todas as escolas como iguais e cair em generalizações infundadas, assim como não podemos deixar de considerar e de valorizar aquilo que lhes dá unidade e que se reproduz em todos os espaços independente dos sujeitos que os constroem. (p. 57)

Como dito nas palavras acima, cada escola possui o seu contexto e este interfe nas ações de cada ator, seja ele docente, discente, entre outros que compõem o espaço escolar. Dessa maneira, ao observarmos todo o conjunto de ações e seus atores da escola, poderemos compreender como as diferentes situações afetarão a organização e desenvolvimento do trabalho do professor.

A estrutura da escola está dividida a fim de organizar e coordenar as atividades desenvolvidas pelas pessoas que ali atuam de acordo com os aspectos físicos, humanos, financeiros, jurídicos, administrativos e econômicos. Nesta estrutura encontramos uma diversidade de ações específicas do meio escolar que variam de escola para escola. Essa diversidade de ações é prevista no regimento escolar e nas normativas e planos estaduais e municipais. Tais documentos visam a regulamentar o trabalho de cada escola, sem deixar de dar-Ihe autonomia para se organizar de acordo com as especificidades de seu contexto.

As coordenações das ações escolares contam com as orientações políticas-normativas e com certas perspectivas teóricas que esclarecem algumas situações complexas que possam ocorrer. As leis e parâmetros que regem a escola, como por exemplo, a implantação da reforma na educação brasileira pela Lei de Diretrizes e Bases da Educação em 1996 trouxeram diversas mudanças às leis anteriores, como a inclusão da educação infantil, assim como a formação adequada dos profissionais da educação básica.

É pela forma que a escola se organiza e se estrutura que podemos identificar as características da gestão de cada meio escolar, ou seja, as suas singularidades. Desta maneira poderemos identificar as relações de poder, os elementos arbitrários, produzidos e reproduzidos em termos históricos e socioculturais da escola.

Quando concebemos a escola como lócus do trabalho docente, a organização e a gestão da escola como prática educativa passam a adquirir um valor mais amplo nas suas atitudes e no modo de agir. Todavia, essas ações devem assegurar as condições pedagógicas e organizacionais para que se consiga alcançar uma qualidade cognitiva das aprendizagens, isto é, do desenvolvimento mental de seus alunos e favorecer o trabalho dos professores para atingir tal objetivo. No entanto, a maioria das organizações escolares estão sujeitas a um controle burocrático com arranjos estruturais formais pré-determinados. Tanto a organização, quanto a estrutura seguem um modelo uniforme imposto em todo o país.

Desta maneira, para que as ações e os trabalhadores sejam coordenados de forma eficiente é fundamental o papel do gestor na realização do trabalho escolar. Conforme Paro (apud Motta; Pereira, 2008, p.17), "não existe organização sem administração e a recíproca é quase sempre totalmente verdadeira, já que é essencial dentro das organizações que a 
administração seja exercida". O uso do termo gestão quando aplicado a administração escolar é relativamente recente. O gestor escolar tem que ter a consciência de que ele, sozinho, não pode administrar todos os problemas da escola. O caminho é o compartilhamento de responsabilidades entre alunos, pais, professores e funcionários. $O$ diretor deve incentivar a participação, respeitando as pessoas e suas opiniões. Teremos então uma gestão democrática, onde todos os atores envolvidos no processo participam das decisões coletivamente.

Desta maneira o gestor assume o papel de líder cooperativo, ou seja, alguém que consegue aglutinar as aspirações, os desejos, as expectativas da comunidade escolar e articular a adesão e a participação de todos os segmentos da escola em um projeto comum. O diretor deverá atender às questões escolares de maneira que contemple a todos os aspectos pedagógicos, administrativos, financeiros e culturais. Podemos dizer que o gestor é o mediador entre escola e comunidade. $O$ diretor deve incentivar a participação, respeitando as pessoas e suas opiniões. Para Paro,

o gestor escolar deve ser um líder pedagógico que apoia o estabelecimento das prioridades, avaliando, participando na elaboração de programas de ensino e de programas de desenvolvimento e capacitação de funcionários, incentivando a sua equipe a descobrir o que é necessário para dar um passo à frente, auxiliando os profissionais a melhor compreender a realidade educacional em que atuam, cooperando na solução de problemas pedagógicos, estimulando os docentes a debaterem em grupo, a refletirem sobre sua prática pedagógica e a experimentarem novas possibilidades, bem como enfatizando os resultados alcançados pelos alunos. (2008, p.130)

No entanto, muitas vezes, observamos que a figura do gestor da escola pública realiza inúmeras tarefas de caráter burocrático, faltando-lhe tempo para cuidar da parte pedagógica. $\mathrm{Na}$ tentativa de auxiliar o serviço do gestor o funcionamento da escola foi dividida em três áreas, que trabalham interligadas, integradas ou sistêmicas: gestão pedagógica, gestão de recursos humanos e gestão administrativa.

A gestão administrativa tem como função planejar, coordenar e executar as ações da escola e assim assegurar a gestão de recursos humanos, físicos e financeiros, assim como assessorar o gestor pedagógico e o de recursos humanos nas suas funções. A gestão pedagógica possui o lado mais importante e significativo da gestão escolar, pois, os que atuam nessa função estabelecem objetivos, gerais e específicos, para o ensino. No que se refere aos recursos humanos na escola, a direção tem como objetivo a obtenção e manutenção de um quadro de servidores bem formados, capacitados e motivados.

Desse modo a escola poderá garantir que as suas funções frente sociedade sejam elaboradas e executadas a fim de atender as necessidades básicas de seus alunos. Da mesma maneira que poderá garantir que o professor consiga desempenhar suas ações em condições adequadas de trabalho e, consequentemente, o seu desenvolvimento profissional. 


\section{Trabalho docente}

O trabalho docente, como foco de pesquisa, vem passando nas últimas décadas por um processo de crescimento intenso. Observamos na pesquisa de Santos (2011) que, na última década, tivemos uma ampliação dos projetos de pesquisa e nas temáticas com foco na pesquisa sobre o trabalho docente. Algumas dessas pesquisas mostram que o trabalho docente tem-se apresentado como um trabalho contextualizado, concreto, marcado pelas casualidades situacionais. Assim, o trabalho docente passou a ser um trabalho socialmente reconhecido, realizado por um grupo de profissionais específicos de formação especializada.

Considerando a docência como qualquer outro trabalho humano, esta pode ser analisada como uma atividade, afinal, trabalhar é agir em função de um objetivo, atuando em um material para transformá-lo através do uso de técnicas e utensílios. Já ensinar é agir na classe e na escola em função da aprendizagem e da socialização dos alunos, educá-los e instruí-los com a ajuda de programas, métodos, livros, exercícios, normas, etc (Tardiff; Lessard, 2012). Assim, quanto maior for a possibilidade de variabilidade das situações de trabalho, maiores serão as interferências da atividade metal do sujeito, ou seja, das suas características, da maneira de que utiliza os meios na execução dos objetivos atribuídos por ele ao atender às tarefas prescritas.

Desta maneira, tanto o meio afetará o trabalho docente assim, quanto o trabalho docente estará influenciando na formação dos indivíduos e nas possíveis mudanças sociais que poderão ocorrer. Percebemos esse jogo de interferência quando observamos as mudanças exigidas na educação da sociedade por uma melhor preparação na inserção dos indivíduos em uma sociedade que está em constante crescimento industrial, tecnológico e sob novas formas de organização econômica e política. Essas mudanças introduziram novas formas de trabalho e de interação social exigindo que o ensino da população prepare os novos indivíduos para tal realidade.

Os governos consideram a educação escolar como um investimento rentável e visam a aumentar sua eficácia e sua responsabilidade pelas práticas e normas de gestão de organização do trabalho vinda diretamente do ambiente industrial e administrativo. A história evidência que os diferentes interesses políticos e econômicos privilegiados na organização das sociedades têm repercussões abrangentes na organização da educação de cada país. Diante disso, Tardiff e Lessard (2012) afirmam que "pode-se dizer que a escola e o ensino têm sido historicamente invadidos e continuam ainda a sê-lo, por modelos de gestão e de execução do trabalho oriundo diretamente do contexto industrial e de outras organizações econômicas hegemônicas" (p. 25). Neste contexto, a evolução do ensino dentro da escola moderna caracterizou-se pela introdução de controles burocráticos na gestão do trabalho docente.

Foi a partir destas mudanças sociais que a educação começou a se democratizar e a se formalizar em espaços próprios, exigindo a presença de um profissional para encaminhar os processos de ensino. A educação, ao longo da história, vem se adequando aos interesses de cada Estado, o que tem deixado marcas da educação no nosso século. A intervenção do 
Estado sobre os sistemas de ensino assume um quase absoluto controle sobre o trabalho dos profissionais da educação, em especial das Escolas de Educação Básica e dos professores.

As formas de regulação do Estado, quando bem elaboradas, garantem a imparcialidade e a qualidade dos diferentes sistemas que compõem a rede educacional no país. Estas orientações definem a organização e desenvolvimento dos processos de formação de professores, as políticas de valorização e regulamentação da profissão, bem como as formas de investimento e estruturação dos sistemas de ensino. Para Santos (2011), "é necessário que se consiga encontrar um ponto de equilíbrio entre os mecanismos de controle do Estado e a autonomia das escolas e dos professores no gerenciamento de suas ações, na organização e realização de seus trabalhos" (p. 58). Assim, entendemos que o professor necessita de autonomia nas suas reflexões e atuações no desenvolvimento de seu trabalho para que consiga promover uma formação escolar que garanta aos alunos uma leitura mais próxima da realidade e de sua condição de indivíduos sociais.

Conforme as palavras de Contreras (apud Santos, 2011, p. 78) a profissão docente é "uma ocupação socialmente encomendada" e de responsabilidade pública em que as decisões não podem ser tomadas pelo professor individual e solitariamente em suas salas de aula, pois, o trabalho docente exerce forte influência social. Logo, o trabalho docente exige das pessoas que o exercem uma responsabilidade além do esperado, pois, "um professor não trabalha sobre os alunos, mas com e para os alunos, e precisa preocupar-se com eles" (Tardif; Lessard, 2012, p. 70). Cada aluno apresenta suas características socioeconômicas, valores, crenças e interesses que condicionam o trabalho docente e o professor deve ajustarse a essas características. Os compromissos sociais e profissionais assumidos de forma ética e crítica pelo professor sustentam-se em conhecimentos e saberes profissionais que possibilitam a análise das situações e a transformação das mesmas.

Desta maneira,a atividade do professor não está mais centrada meramente no conteúdo, mas sim como ele age para ensinar os seus alunos, ou seja, como ele planeja, pensa, trabalha e como faz para que os alunos se insiram nas atividades propostas. A atividade de preparação envolve uma série de ações, como: o planejamento de longo, médio e curtos prazos de aprendizagem, a efetivação dos conteúdos, a adaptação da matéria em função das preocupações efetivas dos alunos, de seus interesses, de sua idade, de seus conhecimentos anteriores, a preparação de exercícios e de material pedagógico, etc. Essa fase do trabalho docente acontece em vários momentos do ano escolar: no começo do ano, nos períodos importantes, antes de cada aula, nas novas atividades.

A docência também é atuação, participação e colaboração em outros espaços da escola e do sistema educativo. É nesse conjunto de ações que o professor realiza temos diversos elementos que se integram e que são condicionantes do trabalho docente. Em síntese, os principais condicionantes do trabalho docente são: a rede escolar em que a sua escola se insere, a própria escola e o próprio professor com suas características pessoais e profissionais. Temos ainda alguns dos aspectos condicionantes da atividade relacionados às 
características pessoais e profissionais dos professores como: gênero, idade, tempo de atuação na profissão, tempo de atuação na escola, carga horária de trabalho, formação inicial, experiência profissional, investimento na carreira, entre outros.

Podemos identificar as situações características do contexto escolar, as quais compõem o trabalho dos professores, em dois grandes grupos: aqueles relacionados à rede escolar e aqueles relacionados à escola. Com relação à rede escolar há aqueles aspectos relacionados à carreira docente dos professores como: as formas de seleção dos professores e as formas de contratação dos professores, as políticas públicas vigentes. Com relação à escola, podemos citar os objetivos institucionais, o projeto político-pedagógico, as formas de organização do trabalho escolar, os recursos financeiros, os alunos, a comunidade escolar.

Outro aspecto que influencia na maneira que o professor irá atuar é a formação inicial. Durante esse processo de formação profissional os paradigmas são formados e definirá a forma como o trabalho docente é realizado. $O$ trabalho realizado pelo docente possui dois momentos distintos: um momento em que o professor age de maneira que outros não observam, ou seja, são as atividades mentais que resultam em novos conhecimentos, planos e reflexões, e as ações visíveis e observáveis, que se concretizam nos registros produzidos pelo docente na organização e no planejamento do seu trabalho.

No entanto, a maneira adotada pelo professor para realizar o seu trabalho refletirá no seu processo de desenvolvimento profissional e no modo em que supera as dificuldades encontradas no seu dia-a-dia. Desta maneira entendemos que é primordial o professor vivenciar durante toda a sua vida profissional, ou seja, processos de aprendizagem permanente, o que chamamos de formação continuada. Todavia, a construção de conhecimento permanente muitas vezes não é incentivada pelo sistema de educação.

Apenas com a evolução nos estudos no campo da formação continuada é que podemos dizer que essa falta de incentivo está sofrendo um processo de mudanças, pois passou ser uma das preocupações de estudiosos da área. Marcelo (1999) define esse processo:

A formação de professores é a área de conhecimentos, investigação e de propostas teóricas e práticas que, no âmbito da Didática e da Organização Escolar, estuda os processos através dos quais o professor em formação ou em exercício se implicam individualmente ou em equipe, em experiências de aprendizagem através das quais adquirem ou melhoram os seus conhecimentos, competências e disposições, e que lhes permite intervir profissionalmente no desenvolvimento do seu ensino, do currículo e da escola, com o objetivo de melhorar a qualidade de educação que os alunos recebem. (p. 26)

Da mesma maneira consideramos que nos processos de formação os sujeitos envolvidos aprendem e desenvolvem suas competências profissionais de forma organizada, a fim de potencializar mudanças consistentes na realização das suas atividades centradas nos seus interesses e necessidades. Este processo de formação de professores deve ser um processo contínuo, com fases diferenciadas, mas que deve conter princípios didáticos e 
pedagógicos comuns. A formação deve integrar-se em processos de mudanças, inovação e desenvolvimento curricular, como estratégia para facilitar o ensino. E ainda, fazendo-se necessário ligar esse processo de formação de professores com o desenvolvimento organizacional da escola para que, assim, a formação busque resolver problemas próprios do contexto dos professores, com maior potencialidade para transformação da escola.

Esse processo de formação deve articular os conteúdos propriamente acadêmicos e disciplinares com os conhecimentos pedagógicos dos professores, e assim estruturar o pensamento do professor, além de integrar teoria e prática na formação de professores, de modo que o ato de aprender a ensinar seja realizado através de um currículo orientado para a própria ação. Logo as transformações e melhorias ocorrem quando o professor busca tornar-se o agente da sua própria formação.

O processo de formação do professor não pode ser pautado somente pelas delimitações de seu trabalho dentro da sala de aula. É preciso pensar mais além, tentando compreender como ocorre o desenvolvimento profissional dos professores. De acordo com Marcelo,

destacam que é através da formação e treino profissional com especialistas que os professores acabam por alcançar o objetivo de aquisição de competências, e através do apoio profissional entre colegas, ou individual é uma das estratégias formativa relevante para o desenvolvimento profissional. (1999 apud Oldroyd; Haul, 1999, p.147)

São nesses momentos de proximidade entre os especialistas e professores que o professor adquire conhecimento e competências para o seu desenvolvimento profissional. Assim, o professor poderá assumir um planejamento de desenvolvimento do seu próprio processo de formação, ou seja, o seu desenvolvimento profissional será autônomo. O que resultará em modificações e aperfeiçoamentos no ensino.

Fica evidente a importância de aprofundar a comunicação horizontal entre os professores afim de permitir a interligação entre os mesmos. Para que por meio de discussões, questionamentos e indagações a cerca do professor e do seu trabalho, seja, forjado pela cooperação e colaboração a capacidade de experimentar e aceitar riscos, assim como também, a responsabilidade de estabelecer objetivos e metas integradas com a escola.

\section{Objetivo}

O presente artigo tem por objetivo relatar a pesquisa desenvolvida no âmbito da UFSM. A pesquisa de natureza qualitativa buscou, por meio de entrevistas com professores atuantes em escolas publicas de ensino médio de Santa Maria- Rio Grande do Sul, compreender como os professores articulam os diferentes elementos constitutivos do trabalho docente na sua atuação em escolas públicas de ensino médio. Para tanto, baseou-se em nos questionamentos: como se caracterizam as diferentes ações realizadas pelos professores em serviço no planejamento e realização de seu trabalho nas escolas públicas de ensino 
médio de Santa Maria - RS? Como os professores gerenciam as suas diferentes ações no planejamento e realização de seu trabalho nas escolas públicas de ensino médio de Santa Maria - RS?

\section{Metodologia}

Para a realização das análises das informações que envolvem interações entre indivíduos e entre os indivíduos com o meio, temos que considerar as inúmeras possibilidades que podem surgir, o que se caracteriza em um desafio para as pesquisas no campo da educação.

A escolha pela entrevista como instrumento de coleta justificou-se pela importância do relato do próprio sujeito de pesquisa, dos quais desejávamos obter as informações, permitindo esclarecer dúvidas no momento em conversamos os mesmos. Dessa forma, a entrevista assumiu um papel fundamental no desenvolvimento da pesquisa.

Após termos elaborado o roteiro de entrevista contatamos a coordenação pedagógica de cada escola, nos apresentamos, expomos o objetivo desta pesquisa e convidamos os professores que estivessem dispostos a participar da pesquisa. Somente depois desse contato com a coordenação pedagógica entramos em contato com os professores para marcar um horário disponível para a realização da entrevista. Entrevistamos um total de quinze professores de ensino médio do município de Santa Maria. No entanto, apenas seis entrevistas foram analisadas até esse momento.

Para a organização e a análise das informações obtidas com as entrevistas realizamos a transcrição de todas as entrevistas. Em seguida estabelecemos as categorias a serem analisadas, as quais foram estabelecidas com base nas próprias questões da entrevista. Depois de estabelecidas as categorias elaboramos quadros específicos para cada categoria abordada, onde registramos e agrupamos as respostas dadas.

Após esta etapa de organização das informações realizamos um recorte nestas tabelas, para separarmos todas as ideias centrais, a fim de conseguir trabalhar sobre a totalidade delas. A partir das ideias relevantes, selecionamos as manifestações representativas para serem utilizadas como exemplos no texto que compõe as evidências e os resultados.

\section{Resultados}

A partir das análises das informações apresentamos as evidências que nos permitiram responder nossas questões de pesquisa, bem como os resultados que respondem o problema central. Para tanto, partimos do entendimento de que o trabalho docente é indivisível do ponto de vista de sua realização. Para a sua compreensão suspendemos, momentaneamente, alguns aspectos sem desligá-los do contexto institucional e dos demais aspectos aos quais estão conectados. Assim, para respondermos as questões relacionadas ao trabalho docente nos detemos a aspectos definidos posteriormente a partir de sua recorrência nas manifestações dos professores e da importância por eles atribuída. Desta maneira organizamos conjuntos de informações que, uma vez agrupadas, permitiram responder cada questão de pesquisa. 
Respondendo a primeira questão de pesquisa: Como se caracterizam as diferentes ações realizadas pelos professores em serviço no planejamento e realização de seu trabalho nas escolas públicas de ensino médio de Santa Maria - RS?

Para respondermos a esta questão objetivamos identificar e caracterizar, por meio da explicação dos professores, as ações realizadas pelos professores na organização e realização de seu trabalho. A sistematização destas informações delimitou quatro categorias que guiaram nossa análise, são elas:

Categoria 1: as ações realizadas pelos professores na sala de aula.

Categoria 2: as ações realizadas pelos professores na hora atividade: planejamento, estudo, correção.

Categoria 3: as ações realizadas pelos professores na sua formação continuada.

Categoria 4: as ações realizadas pelos professores em eventos, reuniões, planejamento.

Em relação à categoria 1, as ações realizadas pelos professores na sala de aula, dividimos as informações em subcategorias: as interações entre aluno/professor estabelecidas dentro e fora da sala de aula, a organização dos alunos em sala de aula, as estratégias didáticas adotadas, a gestão do tempo em sala de aula e responsabilidades dos alunos em sala de aula.

Em relação às formas de interações entre aluno/professor, estabelecidas dentro e fora do espaço escolar, percebemos uma variedade de elementos com os quais os professores organizam suas manifestações a respeito. Manifestaçãom da interação entre eles e os alunos se reportando a qualidade das interações, às causas, às formas, aos espaços, aos papéis assumidos: "Me dou bem com os alunos. Acredito que eles também gostem de mim [...] a gente sempre se comunica fora, pelo Face...é um bom relacionamento sim."

A qualidade da interação é atribuída a diferentes fatores. Um dos professores afirma que a interação acontece em função de um "ambiente informal de suas aulas" (PEB 2) e que a liberdade gerada pelas situações didáticas possibilita diferentes foras de comunicação e interação, assim como o "trabalho baseado nos princípios de respeito e confiança" (PEB 2) condiciona as interações entre aluno/professor.

Em contradição aos professores anteriores, o PEB 4 justifica sua boa interação com os alunos ao fato de possuir um relacionamento maternal, ou seja, traz de forma intensa a relação entre docência e maternidade. Justifica este sentimento pelo fato de trabalhar com "alunos carentes de afeto" (PEB 4).

Em relação às formas de organização dos alunos em sala de aula os professores possuem maneiras diferentes para tal, mas sustentam suas atitudes argumentando que é para facilitar o aprendizado, a convivência e o controle da turma. Como por exemplo, o PEB 3 afirma não se deter muito "nessa parte de organização dos alunos", pois afirma não gostar de impor certas regras porque acredita que isso acaba intimidando os alunos, logo, os deixa à vontade para melhor participação deles em aula. Ou seja, ele não impõe lugares e nem formas para a organização dos alunos, mas os mantém no modelo tradicional de organização, em fileiras. O PEB 3 relata ainda que "possui muitos alunos, muitas turmas $e$ 
pouco tempo para dispor na arrumação dos alunos em sala", ou seja, o professor está sobrecarregado e com pouco tempo para planejar e por em prática uma aula mais dinâmica e diferenciada.

A respeito da subcategoria estratégias didáticas adotadas podemos perceber que é muito particular a maneira que cada professor ministra suas aulas. Diante de tantas diferenças é possível notar que a maioria dos professores adapta suas aulas, fazendo o uso de algumas tecnologias diferentes para tentar fugir do quadro e giz, como os PEB 1, PEB 2, e PEB 3 afirmam utilizar algumas vezes em suas aulas, o uso do data show e de salas de informática. Em contrapartida o PEB 5 afirma não conseguir usar tecnologias como sala de informática, pois alega ter "computadores estragados e além disso nós temos um para três, é impossível".

Observamos que os professores tem se esforçado para proporcionar aulas mais dinâmicas com diferentes estratégias didáticas, a fim de estimular um maior interesse e participação dos alunos, embora muitas vezes os recursos oferecidos pela escola não abarcam todas as demandas do dia a dia, além de o que possuem estarem estragados como o relatado pelo PEB 5 .

Em relação a subcategoria gestão do tempo em sala de aula, a maioria dos professores consideram ter muito conteúdo para lecionar, mas pouco tempo de aula. O que dificulta 0 ensino, como relatam alguns professores: PEB 3 acredita que a questão do tempo é algo importante e qual precisa ser planejado e que requer muita atenção, pois "são muita turmas e, muito conteúdos para vencer", para tanto faz um planejamento mensalmente ou trimestralmente, dependendo da quantidade de atividades que ele tem para realizar. $O$ que se assemelha a PEB 5 e PEB 6, que também relatam do escasso tempo em que têm para tal atividade. A PEB 2 expõe suas experiências como um fator facilitador de gerenciar o tempo de suas atividades em aula. Já PEB 1 afirma que suas aulas são dividas em dois momentos: "o primeiro período para conteúdos, e o segundo para dúvidas e atividades relacionadas ao conteúdo" (PEB 1).

Em relação à subcategoria responsabilidade dos alunos em sala de aula, constatamos que cada professor possui um jeito de delegar tarefas aos seus alunos. Porém, existem algumas atitudes comuns entre eles como, por exemplo, PEB5 e PEB6 afirmam que os alunos são responsáveis somente por levarem para as aulas o material solicitado pelo professor. PEB 3 afirma que tem essa atitude de dar liberdade para os alunos porque acredita que assim estimula-o para que queiram participar do desenvolvimento das aulas $\mathrm{e}$ da organização dos conteúdos curriculares.

Em relação à categoria 2, as ações realizadas pelos professores na hora atividade, dividimos as informações coletadas em subcategorias: ações realizadas no planejamento, os parâmetros seguidos para o planejamento, os fatores que interferem no planejamento, as tecnologias utilizadas, os materiais e recursos utilizados, a relação planejamento/escola.

Sobre a descrição das ações de planejamento podemos dizer que todos os professores entrevistados realizam algum tipo de planejamento, porém, cada professor tem um jeito particular de planejar suas aulas. A hora planejamento é valorizada por todos os professores e considerada um fator importante na organização das atividades que deverão ser 
desenvolvidas, assim como também na organização pessoal, dando-Ihes um sentimento de tranquilidade frente à turma. A frequência do planejamento dos professores entrevistados tem sido semanalmente. $O$ uso de um caderno para fazer o registro do seu planejamento também é comum, como vimos nas manifestações dos PEB 1, 5 e 6.

Os anos de serviço tem sido um aliado na hora planejamento, visto que os professores fazem uso das experiências anteriores. Observamos que os professores inicialmente analisam a turma e seu nível de conhecimento em que irão trabalhar para então decidir o conteúdo e a maneira como irão trabalhar, o que demonstra uma preocupação com seus alunos. PEB 3 relatou aceitar ideias e sugestões dos alunos para na escolha dos conteúdos.

Sobre a subcategoria parâmetros seguidos pelos professores, observamos que todos os professores seguem um roteiro estipulado, tanto pelas escolas, quanto pelo vestibular da UFSM e PCNs como parâmetros a ser seguido para a realização do planejamento, como PEB 1: "Tenho, eu sigo o conteúdo do vestibular" (PEB 1). Com a mudança do processo de seleção da UFSM, que até o momento era por meio de um vestibular e agora no ano de 2015 para o Enem, o programa do Enem já começou a ser utilizado como parâmetro para o planejamento. Ressaltamos a manifestação de PEB 3 que relatou dar importância aos assuntos da atualidade e que são de interesse dos alunos.

Em relação à subcategoria fatores que interferem no planejamento, é possível afirmar que existe um número expressivo de problemas citados pelos professores. É perceptível que o tempo para os professores é o fator que mais interfere negativamente no planejamento, como relatado por PEB 3: "Tempo, nós temos que ter tempo, e muitas vezes o tempo é escasso. A gente precisa ter muitas turmas e muitas vezes prejudica um pouco o andamento do planejamento e desenvolvimento dessas atividades" (PEB 3). Apenas PEB 1 relatou que 0 fator interferente no planejamento é a necessidade de ter que renovar suas aulas para despertar o interesse de seus alunos e PEB 5, focou seu relato na falta de interesse dos alunos.

Sobre as subcategorias tecnologias utilizadas e materiais e recursos utilizados, percebemos que todos fazem uso de computadores e que internet é um fator essencial para eles. Alguns professores entenderam como tecnologias os materiais que utilizam em suas aulas. A respeito dos materiais e recursos utilizados pelos professores na hora atividade podemos afirmar que todos eles utilizam livros. Conseguimos observar que alguns professores fazem uso de revistas, como PEB 6, que faz uso de revistas como Saúde, Nova Escola e Mundo Jovem. PEB 2 relatou fazer uso do PCN para orientar a sua preparação de aula

Em relação à subcategoria a relação planejamento/escola, observamos que a escola tem um papel fundamental na atividade dos professores. Os professores seguem 0 posicionamento da escola sobre a maneira em que devem trabalhar de maneira livre para tal. Observamos nas manifestações de PEB 6 que a professora cita várias reuniões chegando em alguns momentos prejudicar a sua hora planejamento. Podemos dizer que as escolas desses professores entrevistados ainda não prioriza a hora planejamento de seus profissionais sendo este um momento de profunda importância para a qualidade de seu trabalho. 
Quando o assunto é planejamento por áreas percebemos que a escola tinha como expectativa que esta ação resultasse no planejamento e avaliação das atividades de ensino, além de estudos coletivos entre os docentes da escola. Todavia, podemos dizer que ainda temos uma grande caminhada nesse sentido, pois entre os seis entrevistados apenas dois conseguiram relatar sobre o planejamento interdisciplinar.

Em relação à categoria 3, ações realizadas pelos professores na sua formação continuada, dividimos as informações em subcategorias: o tipo de formação que participa, os assuntos estudados na formação continuada, os investimentos pessoais para a qualificação profissional, as necessidades formativas que tem ou ter tido, a participação na preparação da formação continuada da escola.

Percebe-se que os todos os professores participam de alguma forma de formação continuada, seja ela oferecida pela escola, coordenadoria ou por interesse próprio. Isso demonstra a importância dada pelos professores à formação continuada. No entanto, nenhum dos professores relatou estar cursando um curso de pós-graduação e tão pouco que a escola oferece a possibilidade de se afastar para este tipo de formação.

Sobre a subcategoria assuntos estudados na formação continuada percebemos que quando a formação é oferecida pela escola os assuntos estão relacionados com as dificuldades encontradas na escola durante 0 ano como, por exemplo, problemas de relacionamento com alunos e deficiências. No caso de PEB 1, PEB 5 e PEB 6, que se aproximam no tema questões de doenças e necessidades especiais dos alunos, esse fato demonstra a fragilidade dos professores quando se deparam com alunos de inclusão e a forma em que foi imposta essa inclusão no sistema de ensino. PEB 1 e PEB 3 afirmam que em sua escola acontece um levantamento sobre os temas que eles gostariam abordar no âmbito da formação continuada.

Sobre a subcategoria investimento pessoal na formação continuada percebemos que a minoria dos professores entrevistados investe verba pessoal e tempo na sua formação. Os que não investem afirmam ter fatores limitadores como falta de tempo e recursos financeiros.

Em relação à subcategoria necessidades formativas observamos todos os professores disseram ter uma no mínimo. Uma das necessidades relatadas foi a falta de preparo do professor que sai de universidades, carência pedagógica, preparação tecnológica e a mudança curricular. Outro ponto citado por PEB 2 e PEB 3 foi sobre as mudanças que ocorrem no ensino e na formação e esses professores que estão em serviço não recebem nenhuma formação para que acompanhem essas mudanças.

Em relação à subcategoria participação dos professores na preparação da formação continuada da escola, a participação é pequena, apenas PEB 6 já participou ativamente na organização da formação continuada. Todos os professores disseram que suas sugestões sobre os temas que deverão ser abordados são levados em consideração na hora de escolher os palestrantes.

Em relação à categoria 4, ações realizadas pelos professores em eventos, reuniões, planejamento, dividimos as informações nas subcategorias: ações que participa na escola, forma de participação nas ações, tempos e espaços utilizados para as ações da escola. 
Em relação à subcategoria ações que participa na escola fora da sala de aula percebemos que todos os professores estão envolvidos nas ações realizadas na escola fora do horário de aula, pois relatam que participam de ações que a escola realiza. Os professores afirmam que as ações ocorrem em sábados letivos e são momentos importantes que proporcionam uma boa interação entre aluno, professor e comunidade. Os alunos participam em todas as ações da escola, o que demonstra o envolvimento do aluno nas atividades escolares.

Em relação à subcategoria papeis assumidos nas ações da escola, podemos afirmar que todos os professores contribuem de alguma forma nas ações da escola, no entanto, se envolvem apenas quando a atividade está relacionada à sua disciplina ou quando é solicitada a sua participação na organização das ações.

Respondendo a segunda questão de pesquisa: como os professores gerenciam as suas diferentes ações no planejamento e realização de seu trabalho nas escolas públicas de ensino médio de santa Maria - RS?

O trabalho dos professores se completa na articulação das ações que compõem o seu cotidiano, ou seja, na gerência das suas responsabilidades do seu processo de trabalho interativo em relação a seu objeto, o aluno. Assim, para realizarmos a análise na maneira em que o professor gere suas ações na realização do seu trabalho é fundamental compreendermos os recursos, os sujeitos, os aspectos diversos levados em consideração pelos professores na realização de suas atividades profissionais. Objetivamos identificar e analisar, por meio da explicação dos professores, os aspectos condicionantes de suas situações de trabalho. A organização destas informações delimitou três aspectos que guiaram nossas análises:

1. Os tempos e espaços utilizados para a realização das atividades de planejamento, formação e ações na escola.

2. Os recursos tecnológicos e materiais utilizados pelos professores nas atividades de planejamento, formação e ações na escola.

3. Os sujeitos que participam das atividades dos professores.

Em relação aos tempos e espaços utilizados pelos professores no planejamento observamos que os professores estão se organizando para realizar o seu planejamento semanalmente e no espaço escolar. Como os professores entrevistados têm, pelo menos, mais de 10 anos de serviço, eles já criaram uma rotina de trabalho a fim de se organizar no ambiente escolar. Conforme os relatos, as escolas em questão também estão se organizando para criar tempos para o planejamento por área.

No que diz respeito aos tempos e espaços de formação percebemos que, na maioria, os professores salientam a importância da formação no seu trabalho. Os professores relatam que não recebem incentivos da escola para realizarem uma formação além da formação que é oferecida por ela. Apenas PEB 3 mencionou o seu interesse em realizar um mestrado e doutorado. Entendemos que essa falta de interesse dos demais professores está relacionada com a falta de incentivo da parte da rede de ensino e com a baixa remuneração no salário. 
No que diz respeito aos recursos tecnológicos e materiais utilizados pelos professores nas atividades de planejamento percebemos que, de modo em geral, todos os professores fazem uso da internet, computadores, revistas e o projetor de multimídia tem sido um dos recursos mais utilizados na escola. O projetor de multimídia está presente nas aulas, na formação e nas ações realizadas pela escola fora da sala de aula. Podemos dizer que a tecnologia está presente no trabalho dos professores, mas temos um contrassenso, pois, como constatado em alguns dos relatos alguns dos professores ainda não estão preparados para todas as tecnologias que surgem a cada dia.

No que se refere aos sujeitos envolvidos no planejamento, formação e nas ações fora da sala da sala de aula, constatamos nos relatos que as escolas estão se organizando para que haja o planejamento por área, em que teremos todos os professores envolvidos no planejamento, mas ainda não está ocorrendo de forma uniforme em todas as escolas, como citado pelos PEB 1 e PEB 2. Nos dois casos podemos dizer que os professores acreditam que realizam um trabalho interdisciplinar, pois PEB 1 relatou apenas combinarem a forma em que avalizarão os alunos.

Os sujeitos envolvidos na formação citada por todos os professores tem sido a participação do corpo docente, direção, coordenação e convidados para palestrarem. Apenas foram citadas formações que ocorrem na própria escola e no que se refere às ações na escola fora da sala de aula temos a presença de palestrantes, alunos e a comunidade escolar.

\section{Conclusões}

No que se refere à primeira questão sobre as ações dos professores na organização e preparação de seu trabalho podemos dizer que os professores conseguiram condicionar o seu trabalho às características de seus alunos e superar a resistência que existe em um grupo de alunos para atingir os seus objetivos como docente. Possuem uma boa interação com os alunos dentro da sala de aula, mostrando que conseguem gerenciar o coletivo. Alguns fatores contribuíram para essa boa interação mesmo diante de todas as tensões da profissão: a relação de respeito e confiança; os conteúdos trabalhados relacionados ao cotidiano e interesse dos alunos. Esses fatores demonstram que os professores possuem a capacidade de flexibilização ocupacional e adaptação ao objeto de trabalho. Assim, a transmissão de conteúdos e a socialização, aprendizagem e disciplina se completaram no exercício de ensinar.

Podemos dizer que o ensino ainda se encontra hierarquizado, pois o professor é o detentor do conhecimento e os alunos possuem pouca responsabilidade na organização e desenvolvimento das aulas. O tamanho da turma mostrou-se ser um fator desgaste e determinante nas ações em sala, assim com na organização dos alunos em sala e no próprio planejamento das ações dos professores.

A experiência de trabalho, ou seja, a aprendizagem e domínio progressivo das situações de trabalho ao longo da prática cotidiana, tem se mostrado um fator importante na qualificação da profissão docente, pois, está se aprendendo a ensinar, ensinando e, assim, 
podemos dizer que os professores estão aprendendo solitariamente a docência e, sua experiência de trabalho se cristaliza nas rotinas de trabalho, o que permitem ao professor dominar as situações cotidianas e atingir seus objetivos.

O planejamento de ensino, tarefa considerada importante na docência, é realizado regularmente por todos os professores entrevistados. A importância do planejamento se concretizou por ser o auxílio para organizar as atividades que deverão ser desenvolvidas, assim como também na organização pessoal, proporcionando-lhes um sentimento de tranquilidade frente à turma. O planejamento pode ocorrer diferentes tempos e espaços e, de acordo com os entrevistados, a preferência de modo geral é pelo planejamento semanalmente e na escola.

Constatamos que o planejamento possui laços estreitos com os programas e os objetivos escolares, mas o professor está constantemente revisando, modificando, retirando ou acrescentando elementos para o ano em curso, muitas vezes, os professores não conseguem cobrir todo o programa. Assim, podemos dizer que o planejamento dos professores entrevistados é flexível o suficiente para permitir modificações vindas pelas ideias e sugestões da escola e ou dos alunos na escolha dos conteúdos.

A escola, diante das suas dificuldades e carências, tem buscado conhecer os assuntos de interesses dos professores antes de organizar os momentos de formação na tentativa de suprir as deficiências e dificuldades dos docentes. Com isso podemos dizer que os professores são sujeitos ativos na sua própria formação a fim de aprimorarem o que eles fazem. Dessa maneira, os professores são ativos também na tentativa de suprir as necessidades formativas quando relatam ter buscado cursos por conta própria. Os professores relataram estarem envolvidos nas ações extras sala de aula, pois são nesses momentos que os professores interagem de maneira informal com os alunos e comunidade e podem desenvolver uma relação positiva e enriquecedora entre aluno, professor e comunidade.

No que se refere à segunda questão de pesquisa, sobre como os professores gerenciam as diferentes ações na organização e na realização de seu trabalho, podemos dizer que os professores articulam e realizam o planejamento de maneira criativa, flexível e individual, em função das ações em sala de aula, assim como, em função das orientações da escola. Percebemos essa articulação quando os professores relatam realizar o seu planejamento semanalmente nos espaços escolares, considerando as particularidades de cada aluno e cada turma: suas dificuldades, nível de ensino.

Os professores se empenham em seus planejamentos para encontrarem uma melhor maneira de expor os conceitos científicos, a fim de alcançar uma melhor aprendizagem, assim como também desenvolver a socialização, disciplina, cooperação e participação dos alunos. Muitas vezes suas ações ocorrem por meio de improvisações, pois, falta-lhes tempo e espaço próprio para o planejamento na escola. Os professores acabam realizando manobras para conseguir dar conta de todas as atividades na realização de seu trabalho: interagir com os pares, trocar materiais, combinar atividades conjuntas, enfim, participarem da vida escolar. 
A elevada carga horária de contrato dos professores afeta tanto as ações na sala de aula, quanto o planejamento, assim como no tempo disponível para realizar um curso de formação e ou uma ação diferenciada na escola. Logo, essa falta de tempo dos professores afeta o trabalho intelectual e reflexivo. Diante disso percebemos que a ideia que se consolidou entre os professores foi a necessidade de improvisar e simplificar as ações para ganhar tempo, negligenciando assim, a qualidade e a complexidade da maioria das ações escolares, em decorrência da improvisação.

Em relação à formação continuada percebe-se, segundo os relatos, que a principal forma de formação são os momentos de formação que ocorrem no início ou no meio do ano letivo na própria escola. O trabalho docente é visto como uma atividade essencialmente prática, para o qual não são necessárias atividades intelectuais e reflexivas. Contudo, percebemos que a situação dos professores e da escola não representa simplesmente a escassez de recursos, mas também a materialização da desvalorização do seu trabalho. Desta forma, o professor fica impossibilitado de construir o seu conjunto de conhecimentos próprios, além de não encontrarem no seu trabalho o seu principal processo de identidade e legitimação.

\section{Referências}

CANÁRIO, Rui; RAMOS DO Ó, Jorge (dir.). Avaliação em educação: perspectivas iberoamericanas. Lisboa: UL, 2009.

LIBÂNEO, José Carlos, Organização e gestão da escola: teoria e prática. Goiânia: Alternativa, 2004.

LIBÂNEO, José Carlos, Educação escolar, políticas, estruturas e organização. São Paulo: Cortez, 2005.

LIMA, Licínio C. A escola como organização educativa: uma abordagem sociológica. São Paulo: Cortez, 2011.

MARCELO, C. Formação de professores: para uma mudança educativa. Portugal: Porto, 2005.

MONTERO, Lourdes. A construção do conhecimento profissional docente. Lisboa: Instituto Piaget, 2005.

PARO, Vitor Henrique. Por dentro da escola pública. São Paulo: Xamã, 1996.

PARO, Vitor Henrique. Administração escolar: introdução crítica. São Paulo Cortez, 2008.

SANTOS, Maria Eliza Gama. Elementos constitutivos do trabalho docente em uma escola pública de educação básica: prescrições, atividades e ações. Santa Maria: UFSM, 2010. 342f. Tese (doutorado em educação). Universidade Federal de Santa Maria, Programa de Pós Graduação em Educação.

TARDIF, Maurice; LESSARD, Claude. O trabalho docente: elementos para uma teoria da docência como profissão de interações humanas. Petrópolis: Vozes, 2012. 
Mirian Zimermann é licenciada em Química e especialista em Gestão Educacional pela Universidade Federal de Santa Maria. É professora da educação básica na rede de ensino público de Santa Maria e professora temporária no Instituto Federal Farroupilha de São Vicente do Sul - RS.

Endereço: Rua José Paulo Teixeira, 312 - 97110-750 - Santa Maria - RS - Brasil.

E-mail: mirianzim@hotmail.com.

Recebido em 18 de julho de 2015.

Aceito em 7 de novembro de 2015. 